\title{
ORANGE CULTURE.
}

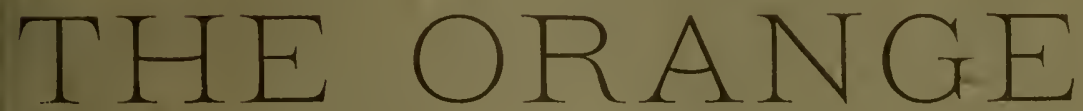

"From Seed to Grove."

By B. M. LELONG, Secretary of the State Board of Horticulture.

EX OFFICIO HORTICULTURAL OFFICER.

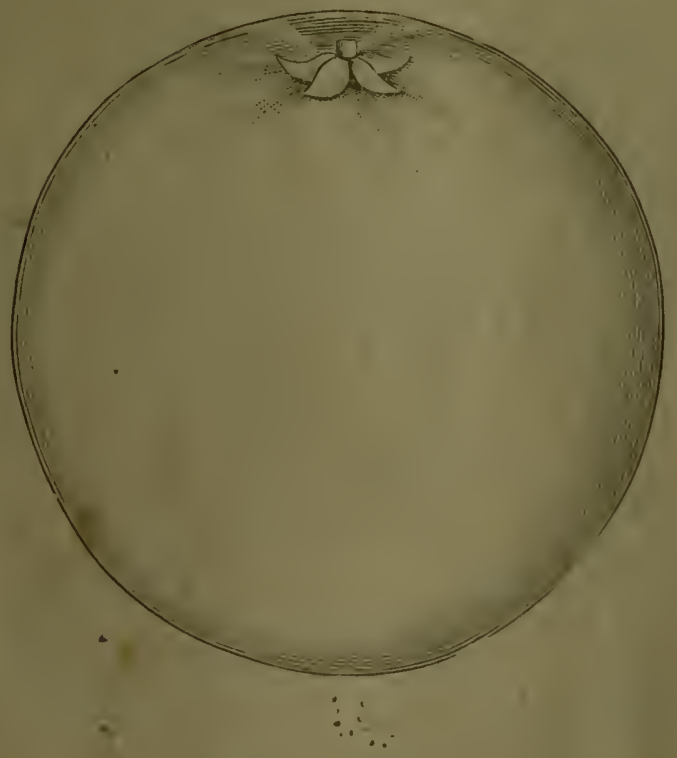

SACRA II ENTO:

STATE OFFICE, : $::::::$ J. D. YOUNG, SUPT. STATE PRINTING. 1890 . 



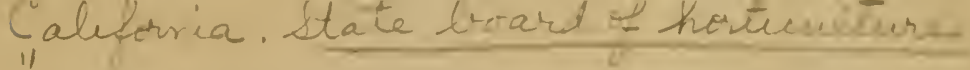

\section{ORANGE CULITURE.}
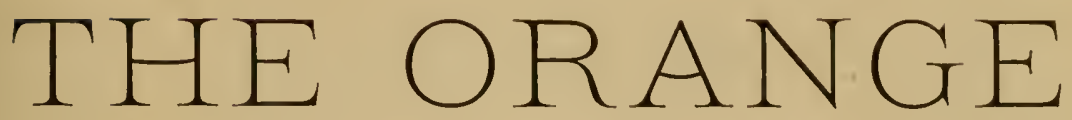

"From Seed to Grove."

By B. M. LELONG, Secretary of the State Board of Horticulture.

EX OFFICIO HORTICULTURAL OFFICER.

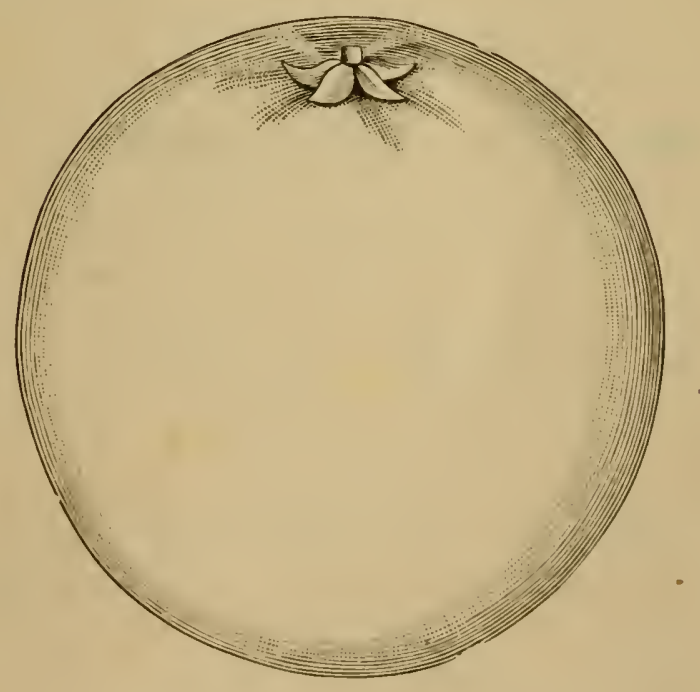

SACRAMENTO:

S'RATE OFHIC, : : : : : : $:$ J. D. YOUNG, SUPT. STATE PRINTING.

1890 . 


$$
\begin{array}{r}
53369 \\
8,2 \\
1890
\end{array}
$$

Gift. Mis. Lia at Stivis. Aus. 10, 19t 


\section{STATE BOARD OF HORTICULTURE.}

\section{OFFICERS AND MEMBERS.}

ELLIVOOD COOPKR, President... Santa Barbara,

Commissioner for the Los Angeles District.

L. W. BUCK, Vice-President Vacarille,

Commissioner for the Napa Distriet.

S. RUNYON, Treasurer Courtlani

Commissioner for the Saeramento District.

J. L. MOSHER, Auditor San Francisco,

Commissioner for the State at Large.

FRANK A. KIMBALL.

Commissioner for the State at Large.

A. F. WHITE Santal Rosil

Commissioner for the Sonoma District.

FRED. C. MILES

Commissioner for the E1 Dorado 1)istrict.

I. H. THOMAS. Visalia

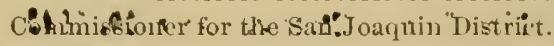

Penry'n,

A. BLOCK

Commissioner for the San Francisco District. Santa Clara,

\section{EXECUTIVE COMMITTEE.}

ELLWOOD COOPER.

J. L. MOSHER, Chairman.

FRANK A. KIMIBALI.

1). M. LELONG, Secretary Ex officio Horticultural nflicer. ALEXANDER CRAW, Quarantine Ofticer Ex oflicio Iintomologist. ELLA F. HALLAIIAN Clerk. IIARRY STANLEY Mesicuger.

Otfice of the Board:

No. 220 Sutter Street, Six Frixcisco. 



\section{PREFATORY.}

This special bulletin treating exclusively on the culture of the orange "from seed to grove," is published in answer to the demand made on this Board for information on the subject, for gratuitous distribution at the State Citrus Fairs of 1891. 



\section{ORANGE CULTURE.}

By B. M. Leunsi, Secretary State Board of Horticulture, ex ofticio Horticultural Ofticer.

\section{THE ORANGE. \\ "FROM SEED TO GROVE."}

"Whence came this delectable fruit, fit for the gods? What was its original history? Was it stolen by some mythological hero from Elysium, like the fire by Prometheus?"

I.

The orange (Citrus aurantium) belongs to the natural order Aurantiacex, and the origin of the different members of this family is extremely

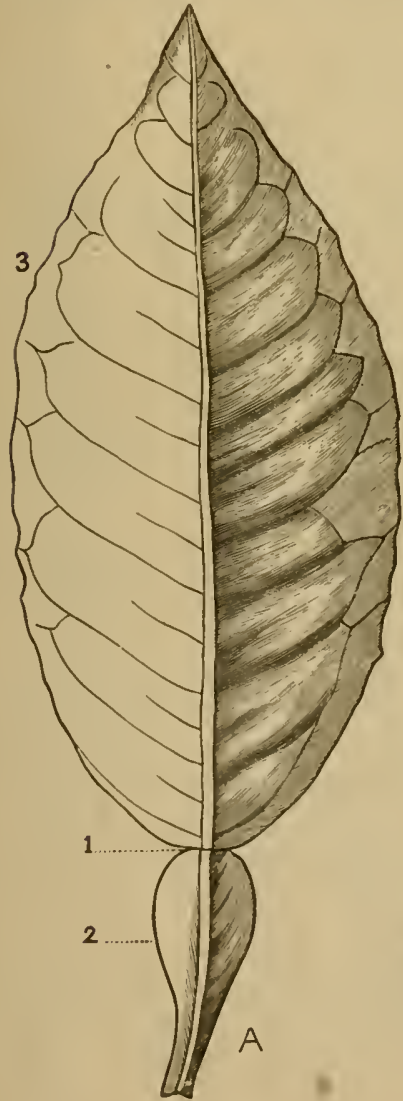

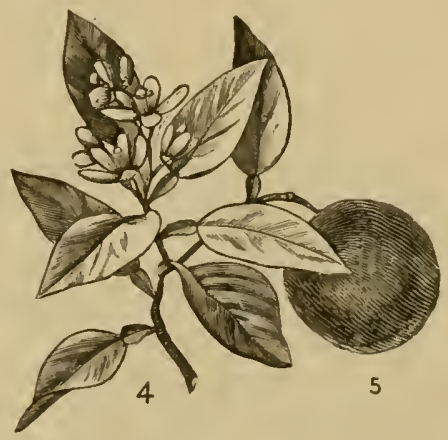
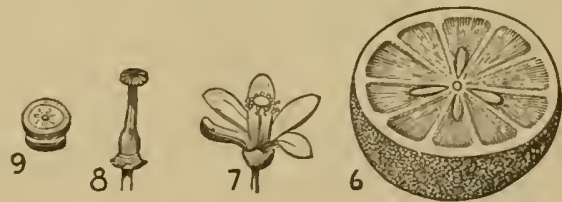

A. Compound unifoliate leat of the orange (Citrus (urautium). 1. Point of mnion, marked by an articulation; 2. Petiole, winged on either side; 3. Lamina; 4. Flowering branch; 5 and 6 . The fruit; 7 . Flower conplete; 8. Pistil; 9. Trankierse section of ovary.]

doubtful, having been cultivated from a remote period of antiquity, but belongs originally to China and India. 
The flowers of the sweet orange are white, the leaves lanceolate or oblong. The petiole is not so marked or winged as in the bitter and sour oranges, but is always present to a greater or less degree. The fruit is generally an oblate sphere, of a golden yellow color; when ripe it is full of delicate pulp and sweet, refreshing juice.

The sour orange (Citrus bigaradia) does not grow quite so high as the sweet orange; has a larger leaf, with a highly winged petiole. The flower is larger and more highly perfumed; the fruit is of a red orange color; the skin rugged and porous; pulp, yellow; juice, extremely bitter.

The bitter orange (Citrus bergamia) is of a dwarf habit; the flowers are small, white, and highly scented; leaves, elongated, acute-the underside quite pale; the petiole is more or less winged; fruit, pale yellow; pulp, bitter.

There are many varieties of sour and of bitter oranges-some bearing large fruits, the majority of which are worthless, and some bearing small fruit, which is valuable for the manufacture of essence of orange and essential oils. The peel of the bitter orange is used in medicine as an aromatic tonic, and the fruit is also used in making marmalade and preserves. Many of these are grown in Europe for the essential oil they contain, from which is made a substance known as bergamot camphor.

\section{II.}

\section{PROPAGATION.}

The Seed.-The seed of the orange has seldom been known to produce fruit equal to that of the parent tree. However, it comes truer to seed than most fruits.

Collecting the Seed.-The fruit is piled into heaps or put into barrels to rot. When it has decayed so that it will break into many pieces when handled, it is crushed in a tub or barrel and the seed is washed out. A coarse sieve is used; the soft substance of the fruit will pass through the wires, leaving the seed in the sieve. This operation is carried on in a place where water can be used freely, as considerable is required to do the work properly.

Keeping the Seed.-To insure best results, the seed of the orange should not be allowed to dry after being taken from the fruit. If not ready to plant them, they should be put in moist sand. In this way they can be kept until everything is prepared.

How to Put the Seed in Sand.-Take a shallow box, say five inches deep and not more than thirty inches square; fill it half full of moist sand, then put the seed on top, about two inches deep, and throw on the top of the seed considerable sand and mix it together with the hands. This is done so that the sand will stick to the seeds and prevent them adhering to each other. Then fill up the box with sand and let them remain until they are to be planted. The boxes can be stacked one upon the other.

Taking the Seed out of the Sand.-The seed-bed having been prepared, have a coarse sieve and take the top box and dump its contents into the sieve. This must be done with care, so as not to bruise the seed. Then shake the sieve, the sand will pass throngh, leaving the seed in the sieve. 
The Seed-Bed.-The seed-bed should be inclosed with boards eighteen or twenty inches wide, set on edge, about four or six feet apart. The bottom should be floored, so as to prevent gophers and ground moles from entering the seed-bed. Laths arc nailed on top, leaving a space of one half inch between them, to protect the sced from being scratched up by the birds. A covering of thin muslin is put on top of the laths to protect the young plants from being scorched by the sun. If the weather be cloudy, it is well that the covering be removed to allow the bed to get warm. It is better to plant the seed thickly and broadcast; as all plants are to be removed, it does not matter how thick they come up. The seeds should be covered with fine, rich soil, from one to two inches.

Time of Planting the Seed.-Planting the seed very early, as in January and February, does not give good results, because it is entirely too early; the seed generally decays, as the time for it to germinate is not till spring. March, April, and even May, are the best months to plant the seed, as the ground is then warm and all danger of frost is over. The seed-bed should be kept moist, but not too wet.

Transplanting.-In one year the plants will be large enough to be transplanted in nursery form. The plants should be sorted; the very small and delicate ones should be planted in shallow boxes by themselves, and kept another year; being so small and delicate, they are generally scorched by the sun when planted in the open ground, and remain small in the nursery.

Distance of Nursery Rows.-The rows should be far enough apart to admit a cultivator between them. Grave mistakes are often made in setting them less than four feet apart, as after being budded many buds are knocked off in cultivating by the horse or the traces rubbing against them. Preference is given to rows when set five or six feet apart. This will give ample room for cultivation; and also, when in digging up trees, a small, narrow sled can be run in to haul them to the head of the rows without rubbing against the nursery stock.

Distance in Nursery Rows.-Planting close together in the rows will tend to make feeble and slender trees. If it is not intended to sack the trees when they are to be transplanted, then the plants can be set from eight to twelve inches apart, and they will make strong and thrifty stocks; but if it is intended to sack them this is too close. They should be at least eighteen inches apart; this will give the digger enough space to take up trees between others. It also has the advantage that the roots are not cut too short, which is apt to be the case when they are planted close together.

Trimming the Stock.-The plants should not be trimmed until at least one year; after planting they should be left to grow at will the first year. If the plants are trimmed when too young, they will make slender and feeble stock.

In the following spring, as early as possible, say in February, the plants are trimmed, leaving a clear stock. All cuts should be made close, so that they may soon heal over. The brush is then gathered and burned. As the ground becomes packed by the trimmers, it should be loosened by running a cultivator between the rows. 
III.

BUDDING.

Spring Budding.-Generally, in the months of March and April, as soon as the trees begin to puit forth and the sap flows freely, it is then the time to bud citrus trees. Everything should be prepared; no time should be lost, as the buds first inserted will sometimes start in less than three weeks with vigor, and by summer will have a large and thrifty top. The buds should be looked over at least ten days after they are inserted, and all those that show signs of dying should be rebudded, in order to give them an early start, and that they may grow more even with those first budded.

Summer Budding.-Summer budding is generally done in June and July. It is not considered as good as early spring budding, because the buds do not start even; and as the greater portion of them start late, their growth is so tender by the time winter sets in that, if they pass through it, they become prematurely hardened by the cold weather, which sometimes causes the tree to become stunted.

Fall Budding. - Fall budding is generally performed during the months of September, October, and sometimes as late as November. After the strings have been removed they are left to pass the winter in dormant bud, to be started in the spring.

IV.

STARTING AND TRAINING THE BUDS.

Cutting off the Tops.-In the spring, as the nursery trees swell very fast, three weeks is long enough for the strings to remain on them; but the tops should not be cut off then. The strings should be removed, the nursery irrigated and cultivated. This will force new growth, and the tops should then be cut back from four to eight inches above the bud. After the bud has grown about six inches or more it is tied to the stock. When the bud has become stocky and able to support itself, what remains of the top is then cut away. The cut should be made smooth and painted with rubber paint. This helps the wound in healing over, and protects the stock from the action of the atmosphere. Those that have been left to lie dormant through the winter should be cut back in the spring to allow the buds to start, just as soon as the trees begin to show signs of growth. Great care should be used in the cutting of the tops, that it be done at the proper time, and that they be not cut so near the bud as to endanger it. A little brush should be allowed to remain to protect the stock, which is removed after the buds have started.

Starting the Bud.-When the stocks put forth in the spring the buds generally start also, and the suckers being very tender, are removed by hand (thumb pruning), breaking at the touch. Cutting them with a sharp knife has the advantage that no others will grow where so cut, and the cut being made clean will give the tree a smooth body, and as the tree grows very little suckering will be required. When the suckers become strong and are removed by rubbing with the hand, the trunks generally become rough and the suckering much greater. 
When to Plant.-Citrus trees are transplanted at various seasons, preference being given to one of its dormant periods occurring during the year.

Trees transplanted in the winter, when the ground is cold, will remain until spring without growing; therefore, it is better not to transplant citrus trees until the ground begins to get warm. The nearer an orange tree is to starting new growth, the greater its strength and root power, and this is the best time for transplanting; also, after they have made their first growth and before starting the second time in spring.

Balling System.-A narrow trench is made along the row and within six inches of the tree, the tap-root is cut about eighteen inches or so deep; then with a spade a round, oblong ball is cut, leaving in it the tree. The spade should be very sharp, or in cutting the roots the jar will break the ball. Pruning shears are used in eutting large roots. When trees are taken up with a sound ball of earth the leaves will hardly wilt.

Puddling System.-Puddling is practiced where the soil is so loose that sacking is rendered impossible. Many prefer this system to any other, as it gires the trees larger and more roots; and where all due precantions are taken, puddling is the best system, and considerable expense is saved.

The Puddle.-A hole is made in the ground and filled half full of water, then soil is thrown into it and worked with a hoe, which forms the puddle. The puddle should be thin enough, so that when the roots of trees are put into it, it will stick to them, at the same time wetting every part thoroughly. The trees are carefully taken up; the soil is shaken from the roots and they are immediately dipped into the mud, or puddle. They are then placed on wet straw in a wagon. $\Lambda$ large canvas, or covering, is placed over the wagon to prevent the sun from drying the roots, as the roots should not be exposed to the sun, even if only for a fer minutes. The wagon is then driven to the field where the holes were dug. The driver hands the trees, one at a time, and the planter holds the trees in position while his men fill it up with dirt, first throwing in the moistest; the planter presses the soil very lightly, and goes to the next one. The tree having been set, a basin is made around it, and a couple of buckets of water poured into the basin; this will settle the soil and keep the tree fresh until water ean be run down the rows in furrows.

Extending the Roots.-It is a common practice among growers to place the tree in the bole, fill it up with soil, and then tramp it. Is the roots are covered with thick mud they will stick together, and if the tree grows it will not do as well as when the roots are extended with care. This is very simple. The hole is half filled with earth so as to form a mound; the shovel handle is driven down in the center, and on being withdrawn a deep hole is left, sufficiently large and deep to admit the tap-root of the tree; then the lateral roots are spread over the mound, as shown in the illustration (Fig. 1), and the soil is lightly pressed. Heavy tramping is not necessary, as the water settles the dirt and keeps the roots in place. As soon as the water in the basin has disappeared, the basin is covered with loose soil; this will prevent evaporation, and also the tree 
from leaning over. Trees planted with these precautions make the best growth and become the most thrifty.

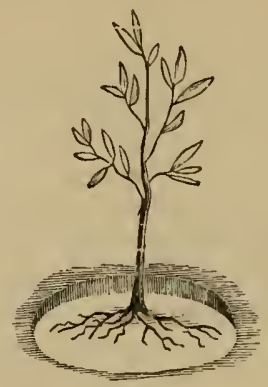

Fig. 1.

Topping the Trees.-When a tree is taken from the nursery the tops should be cut back; the branches should be so cut that in starting they will form a fine-shaped head. This is done because evaporation from the leaves is rapid, and in many cases, where the tops are left on, causes the circulation of the trees to dry, and also the bark will shrivel before the roots have assumed their natural functions.

VI.

PLANTING SYSTEMS AND SOIL.

The planting systems most common in use are the square, triangular, and quincunx. The square system is most generally adopted, being the most simple. In this, the orchard is laid off in lines crossing each other at right angles, with equal intervals of space, and a tree planted at each crossing of the lines.

Soil for Orange Trees. - An orange tree should never be planted on heavy, low ground, or on low, damp ground where water can be reached within a few feet of the surface, and never on black, adobe soil; - they will always be troubled with gum disease, and will also be nipped by frosts every year. A rich, deep, porous soil is absolutely necessary to give the trees a vigorous growth. Trees on heavy adobe or poor soil become stunted and will not produce fine fruit, and never become profitable bearers.

Preparation of the Soil. - The land should be thoroughly worked through the winter and prepared to be planted in the spring, when it becomes warm; also, all weeds and stubble plowed under will be decomposed and serve as a fertilizer to the orchard. The thorough working of the soil liberates crude gases and changes the nutritive principles to a form more readily assimilated by the tree.

VII.

VARIETIES.

The most profitable varieties grown in this State are the following, and their prominence is about in the order named: 
Washington Navel.-Fruit large, solid, and heavy; skin smooth and of a very fine texture; very juicy, highly flavored, with melting pulp; seedless; tree a good and prolific bearer, medium thorny, a rapid grower, although it does not attain a very large size; commenees to bear as early as one year old from the bud; ripens early. Imported from Bahia, Brazil.

Valencia Late.-This orange has proved itself one of the most profitable to grow. It ripens in Nay and June, when other varieties are out of the market. Fruit large, thin skin, pale yellow, firm, oblong, and heavy, very few seeds. An excellent shipper; tree large, and prolific bearer. Imported from England.

Joppa.-This is a remarkable orange, as it can be marketed early and yet able to remain on the trees till July, without deterioration in quality, and for this reason is suitable for all sections. Fruit large (see illustration ), firm, nearly seedless, thin rind, pulp very fine, sweet and juicy, and of rery deep red color; tree thornless, upright, and vigorons grower, suitable for standard purposes. Imported from Palestine.

Mediterranean Sweet.-Fruit medium to large, pulp and skin of very fine texture, very solid, and few seeds; color deep orange; ripens late; tree thornless, of a dwarf habit, inclined to overbear. Imported from the Mediterranean.

Maltese Blood.-Fruit medium, oval, texture and flavor very fine, pulp marked vinous red, very few seeds; fruit shows red color on surface; tree dwarf, thornless. Imported from Mediterranean.

Paper Rind St. Michael.-Fruit small, round, very firm, and juicy; pale thin skin; grows very uniform, ripens late, and keeps well on the tree; does not drop when mature; tree dwarf, medium, thorny, a good and prolific bearer. Imported from the Azores.

Azorean St. Michael.-Fruit medium to large, and solid; pulp fine and melting; medium thin rind; flattened, few seeds; ripens early, and keeps well on the tree; a rapid grower and a prolific bearer; is a large tree, and is recommended for standard purposes. Imported from the Azores.

Wolfskill's Best.-Fruit of excellent quality, somewhat flattened, color deep orange-red, fine grain and pulp; ripens early. This orange is of home origin. The advantage it has over foreign varieties is that the tree is very hardy, and can be planted in localities where the temperature gets so low as to prevent them from thriving; it will also make a larger tree.

Konah.-A California seedling, raised from seed grown on Konah Island; fruit large; rough and thick skin; tree very thorny; ripens early.

Rio.-Fruit and tree resemble the Mediterranean Sweet, but the fruit is much larger, has a thicker skin; ripens late; very seldom can the entire crop be picked from the tree, as it does not ripen even; green oranges are found on the trees thronghout the summer; tree thornless, of a dwarf habit. Imported from the Mediterranean.

Tangierine, or Kid Glove.-Fruit deep red, small, very sweet, and aromatic; when ripe the rind is very easily detached; tree dwarf, very uniform in shape, of a weeping habit.

King. - A late orange, ripening in May and June; averages below medium in size; very rough rind, seginents cleave when fully ripe; very highly flarored. Imported from China.

Satsuma.-Fruit small, flattened; rind very easily detached; of exceedingly fine texture, sweet, and seedless; tree dwarf, and very hardy. Best suited for gardens. 
Kumquat.-Fruit is edible whole (rind and all), very small, oblong, or olive shaped; rind thick, yellow, smooth, sweet scented; very little pulp, and contains many seeds; tree a bush, and very prolific. Best suited for gardens or home plots.

\section{ORNAMENTAL.}

Mandarin.-Tree very ornamental; fruit very red, flattened at the poles, having an outgrowth at the blossom end.

Pomelo (syn. Grape Fruit).-A variety of shaddock; fruit very large, from two to five pounds each, pale yellow, resembling the citron; skin smooth; pulp sub-acid.

Shaddock.-Tree inclined to be dwarf; fruit very large, with smooth skin, pale yellow, and very glossy; the rind is very thick and spongy, and very bitter; ornamental only.

Bouquet.-Fruit very bitter. The flowers have a commercial value, as they are very large and fragrant.

Bergamot.-Ornamental only; fruit large and very rough, flattened. Is grown for the bloom.

IIyrtle Leaf.-Ornamental only; tree very dwarf; foliage densely packed together; small leaf, the shape of the myrtle; fruit bright red, and very bitter.

Variegated Orange.-Ornamental only; tree dwarf; leaf variegated, with white margin and green center; very glossy; stem white and green; fruit striped with white, and very bitter.

\section{VIII.}

PRUNING.

In pruning a tree, especially when allowed to grow for several years without it, considerable work and skill is required. The hot sun should

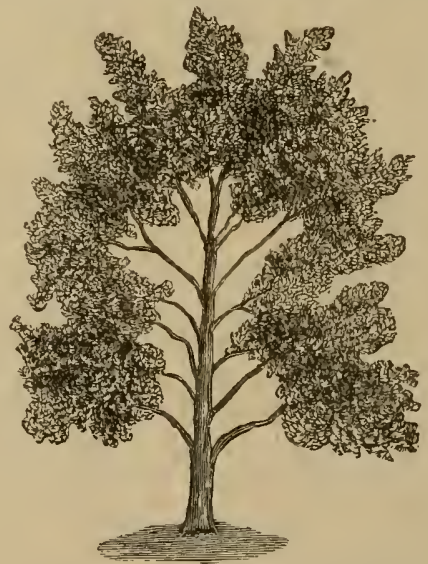

Fig. 2.

not be allowed to enter and scorch the bark, which would also cause the fine brush to die, and a diseased tree is sure to be the result. The advice 
so often given, "that the tree be opened so as to allow plenty of air and sm heat to enter," does not hold good with the orange. Fig. 2 shows how a tree is left after the brush that protects the trunk and branches is removed. The trunk and inside growth is left exposed to the sun.

I have often seen trees with one side of the trunk scorcherd and the bark dead, after the brush that protected it from the sun harl been removed.

Fig. 3 illustrates a high-trained tree of the same age.

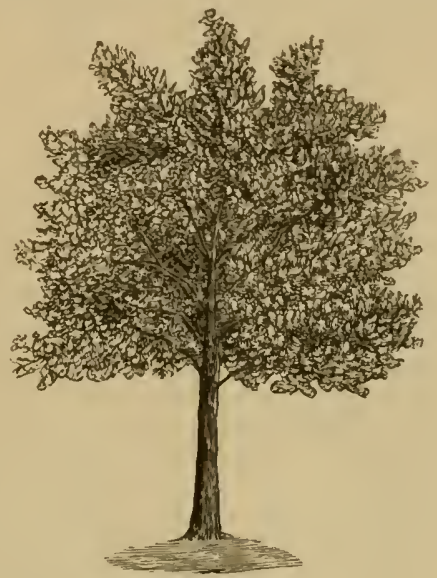

Fig. 3.

In this the lower limbs have been removed, leaving a clean stock, so as to allow the horse in cultivating to pass under its branches and the cultivator to work the gromnd close to the trunk.

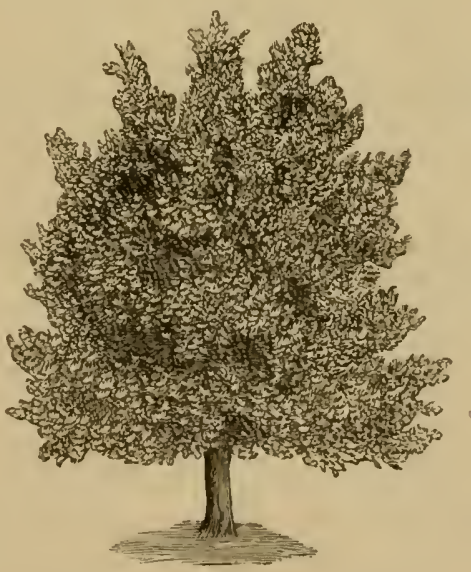

Fig. 4.

Fig. 4 illustrates a low-trained tree of the same age as Figs. 2 and 3. In this the lower limbs have been allowed to remain to protect its trunk and inner growth. 
The inside of the tree is kept clear of all dead wood, and the growth on the outside is allowed to become uniform. The lower foliage supports that above it, and so supports its fruit without the aid of props.

When trees are trained low the shade of the branches keeps the ground moist, and in case of excessive heat, or scarcity of water, will not suffer; whereas, the heat causes the leaves of high-trained trees to curl, and if not watered at the proper time the growth of the fruit becomes checked. Low-trained trees become better balanced, vigorous, healthy, and more productive than when trained high, and the fruit is much more easily and cheaply gathered.

\section{IX.}

THE ORANGE CROP, GATHERING, ETC.

Picking.-The tree should never be picked clean; only the ripe fruit should first be picked, thus lightening up the trees. The clean, bright colored, smooth, fine skin, firm oranges will always command the best prices. Fruit should be handled with care. It is better to (clip) stem cut than to pull the orange, as in pulling there is danger of tearing the skin. The fruit should not be packed fresh from the tree, as when packed it will heat and sweat in the boxes at an ordinary temperature, and, as the entire contents in the box becomes damp, there is great danger from rot and decay. The fruit should be picked in boxes and left in the packing house three or four days, to allow the rind of the fruit to shrink and to lose the surplus moisture in the rind. Unless the weather is very cool they go through a natural sweat, in which the surplus moisture escapes and the rind becomes tough and pliable; many unseen imperfections, such as slight bruises, etc., will develop into spots, necessitating a more careful selection of the perfect fruit for market.

\section{AN ORANGE BOX.}

The standard size of an orange box is twelve inches by twelve by twenty-six and a half, outside measurement, with a partition in the middle.

\section{Standard Counts.}

The standard counts and all the important grades can be more readily understood in the following plans:

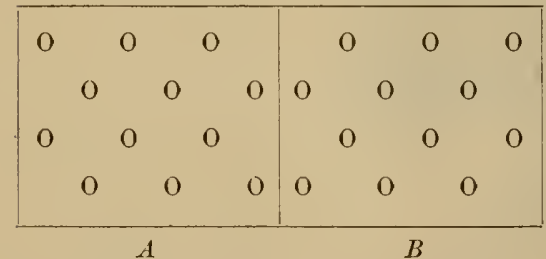

1. Packing 96 to the box; four layers, alternating, as in $\mathrm{A}$ (first layer) and B (second layer).

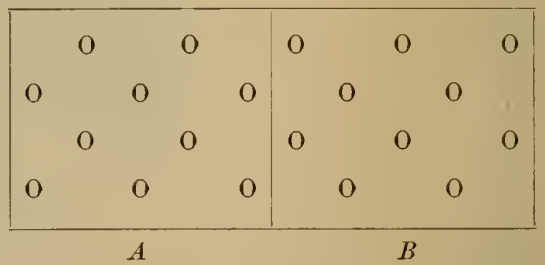

2. Packing 100 to the box; five layers, alternating, as in $A$ (first layer) and $B$ (second layer). 


\begin{tabular}{cccc|cccc}
0 & & 0 & & 0 & 0 & 0 & 0 \\
0 & 0 & 0 & 0 & 0 & 0 & 0 & 0 \\
0 & 0 & 0 & 0 & 0 & 0 & 0 & 0 \\
0 & 0 & 0 & 0 & 0 & 0 & 0 & 0 \\
\hline
\end{tabular}

3. Packing 112 to the box; four layers, alternating, as in $A$ (first layer) and $B$ (second laṿer).

\begin{tabular}{llll|llll}
0 & 0 & 0 & 0 & 0 & 0 & 0 & 0 \\
0 & 0 & 0 & 0 & 0 & 0 & 0 & 0 \\
0 & 0 & 0 & 0 & 0 & 0 & 0 & 0 \\
0 & 0 & 0 & 0 & 0 & 0 & 0 & 0 \\
\hline & 4 & & &
\end{tabular}

5. Packing 128 to the box; four miform layers.

$\left[\begin{array}{llll|lll}0 & 0 & 0 & 0 & 0 & 0 & 0 \\ 0 & 0 & 0 & 0 & 0 & 0 & 0 \\ 0 & 0 & 0 & 0 & 0 & \\ 0 & 11 & 0 & 0 & 0 & 0 & 0 \\ \hline & A & & & B\end{array}\right.$

7. Packing 146 to the box; four lavers as in $A$, and one layer (the second) as in $B$.

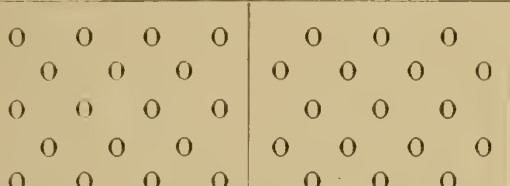

$$
\begin{aligned}
& \text { A } \\
& \text { B }
\end{aligned}
$$

9. Packing 176 to the box : first, third, and fiftl layers as in $A$, and second and fourth layers as in 13.

$$
\begin{aligned}
& \begin{array}{lllllllll}
0 & 0 & 0 & 0 & 0 & 0 & 0 & 0 & 0
\end{array} \\
& \begin{array}{lllllllll}
0 & 0 & 0 & 0 & 0 & 0 & 0 & 0 & 0
\end{array} \\
& \begin{array}{llllllllll}
0 & 0 & 0 & 0 & 0 & 0 & 0 & 0 & 0
\end{array} \\
& \begin{array}{lllllllll}
0 & 0 & 0 & 0 & 0 & 0 & 0 & 0 & 0
\end{array} \\
& \begin{array}{lllllllll}
0 & 0 & 0 & 0 & 0 & 0 & 0 & 0 & 0
\end{array} \\
& 1 \text { B }
\end{aligned}
$$

11. P'acking 226 to the hox; five layers. alternating, as in $A$ (first layer) and if (second layer).

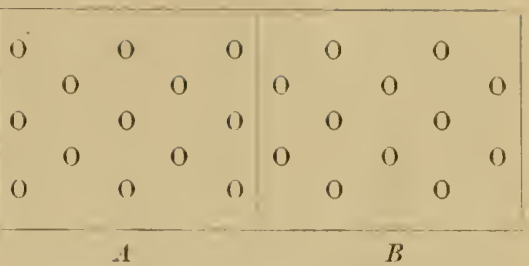

4. Packing 126 to the box; five layers, alternating, as in A (first layer) and B (second layer).

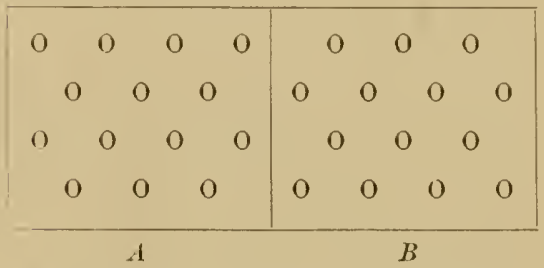

6. Packing 140 to the box; tive layers, alternating, as in $\mathrm{A}$ (first layer) and $\mathrm{B}$ (secoud layer).

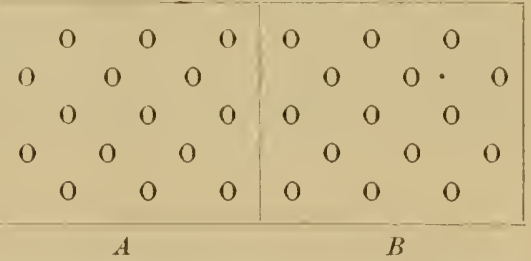

8. Packing 150 to the box; tive layers, alternating, as in A (first layer) and B (second layer).

\begin{tabular}{|llllll|lllllll}
\hline 0 & 0 & 0 & 0 & & 0 & 0 & 0 & 0 \\
0 & 0 & 0 & 0 & 0 & 0 & 0 & 0 \\
0 & 0 & 0 & 0 & 0 & 0 & 0 & 0 \\
0 & 0 & 0 & 0 & 0 & 0 & 0 & 0 & 0 \\
0 & 0 & 0 & 0 & & 0 & 0 & 0 & 0 \\
\hline
\end{tabular}

10. Packing 280 to the box; five layers, alternating, as in $A$ (first layer) and $P$ (second layer).

\begin{tabular}{|llllll|lllllll}
\hline 0 & 0 & & 0 & & 0 & 0 & & 0 & & 0 & \\
0 & & 0 & & 0 & & & 0 & & 0 & & 0 \\
0 & 0 & & 0 & & 0 & 0 & & 0 & & 0 & \\
0 & 0 & 0 & & 0 & & & 0 & & 0 & & 0 \\
0 & & 0 & & 0 & & 0 & & 0 & & 0 & \\
\hline & & $A$ & & & & & & & & \\
\hline
\end{tabular}

Six layers, 1 s in a layer. $A$, tirst layer; $B$, second layer.

The 226 size will pack this size nicely; it is 216 , and packed as shown. 
In packing, it will be to the best advantage to have the end of the box toward the packer, and commence a box of $100,126,150,176$, and 200 with 3 in the first row, 2 in the next, and so on, until you have one layer; then there is a place for each orange. The 112 size goes 4 and 3 in a row, the 216 size 3 and 3 in a row, the 252 size 4 and 3 in a row (a smaller size may be packed-the 294 size-same as the 252 size, putting in one more layer.) There should be a size smaller than the 252 size in the sizer to keep the small oranges out, for if the small ones go in the 252 size they will not pack tight enough.

\begin{tabular}{llllllllll}
0 & 0 & 0 & 0 & 0 & 0 & 0 & 0 & 0 & 0 \\
0 & 0 & 0 & 0 & 0 & 0 & 0 & 0 & 0 & 0 \\
0 & 0 & 0 & 0 & 0 & 0 & 0 & 0 & 0 & 0 \\
0 & 0 & 0 & 0 & 0 & 0 & 0 & 0 & 0 & 0 \\
0 & 0 & 0 & 0 & 0 & 0 & 0 & 0 & 0 & 0 \\
\hline
\end{tabular}

12. Packing 25u to the box; tive uniform layers.

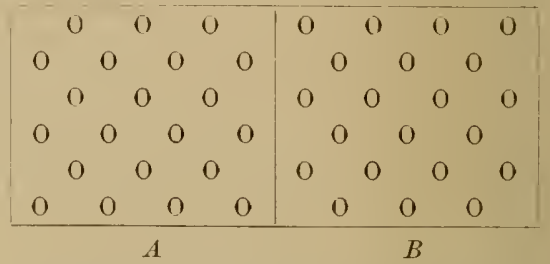

13. Packing 252 to the box; six layers, alternating, as in A (first layer) and $\mathbf{B}$ (second layer).

The arrangement which brings one orange directly on top of another, as in the 128, 146, and 250 sizes (Diagrams 5, 7, and 12), instead of breaking joints, as in the other plans of layering shown, have been discarded by the best packers. It is best to pack oranges upon the dovetail plan, which enables packers to get more oranges in the box and so braced against each other as to be immovable.

\section{Y}

\section{FERTILIZERS.}

Barnyard and sheep manure are the fertilizers mostly employed in the orange orchards in California. They have, to a certain extent, all the essential elements for plant food, but lacking in proportions according to conditions. In fertilizers bulk is not what is necessary, but instead, the proper elements as fertilizers in a concentrated form. Fertilizers in some form can be made to last, like barnyard and sheep manure, and feed several successive crops with a single application. For instance, in ashes and bone we have all the elements for a complete iertilizer, when all that is required is to apply an extra quantity of ashes and a portion of the bone in a coarse state. Ashes are always enduring in their effect, and the coarse bone will be several years in decaying and setting free nitrogen and phosphoric acid. One of the three elements, nitrogen, potash, or phosphoric acid, of which the soil has the least, will always be the measure of the crop. A hundred pounds of potash applied would not give a larger yield than five pounds (and so of the other two elements) if there is not a proportionate increase of the other elements. The right way is to make the most and best manure that is practicable upon the orchard, and piece out with such commercial fertilizers as experiments and experience prove profitable. Artificial fertilizers are of course much more cheaply transported, and, unlike barnyard or sheep manure, do not carry with them seeds of weeds 
into the soil, and as they contain the fertilizing elements in so condensed a form, the whole handling of them becomes much cheaper.

Artificial fertilizers should be applied a little at a time and often. Nitrogen tends to promote leaf growth, and if the bone in the soil does not all decompose in the first year the nitrogen contained in it goes over with it and is not lost. If but one of the elements be used it should by all means be bone, and the finer the bone and the finer and drier the fertilizer, the more valuable it is. When the animal matter in bone decays, the phosphoric acid in the bone is in a reversod condition.

\section{XI.}

DISEASES.

Gum Disease ("Mal de goma").-This disease is first detected on the trunk close to the ground, and is a yellow, gum-like substance which forms on the outside of the bark. It is an exudation of the sap of the tree, which breaks through the bark and forms a gum. The disease is under the bark, and also penetrates into the inner bark and into the wood.

Remedy.-There is but one effectual remedy, $i$. e., cutting array the bark from where the gum oozes, and the infected parts gouged out. If. on the following day, the gum is still rumning, more of the woor must be gouged out until every particle of the disease is removed. Then the wound is corered with rubber paint, or grafting wax, to prevent the action of the atmosphere from cracking the wood left exposed.

"An orange grove charms the eye, satisfies the smell, gratifies the taste, and serves both luxury and art."

In the preparation of this bulletin I have devoted myself to the close observations of the culture of the orange from a commercial standpoint, and to bring about all the practical points bearing on its culture from 'seed to grove." 




$$
\text { b }
$$




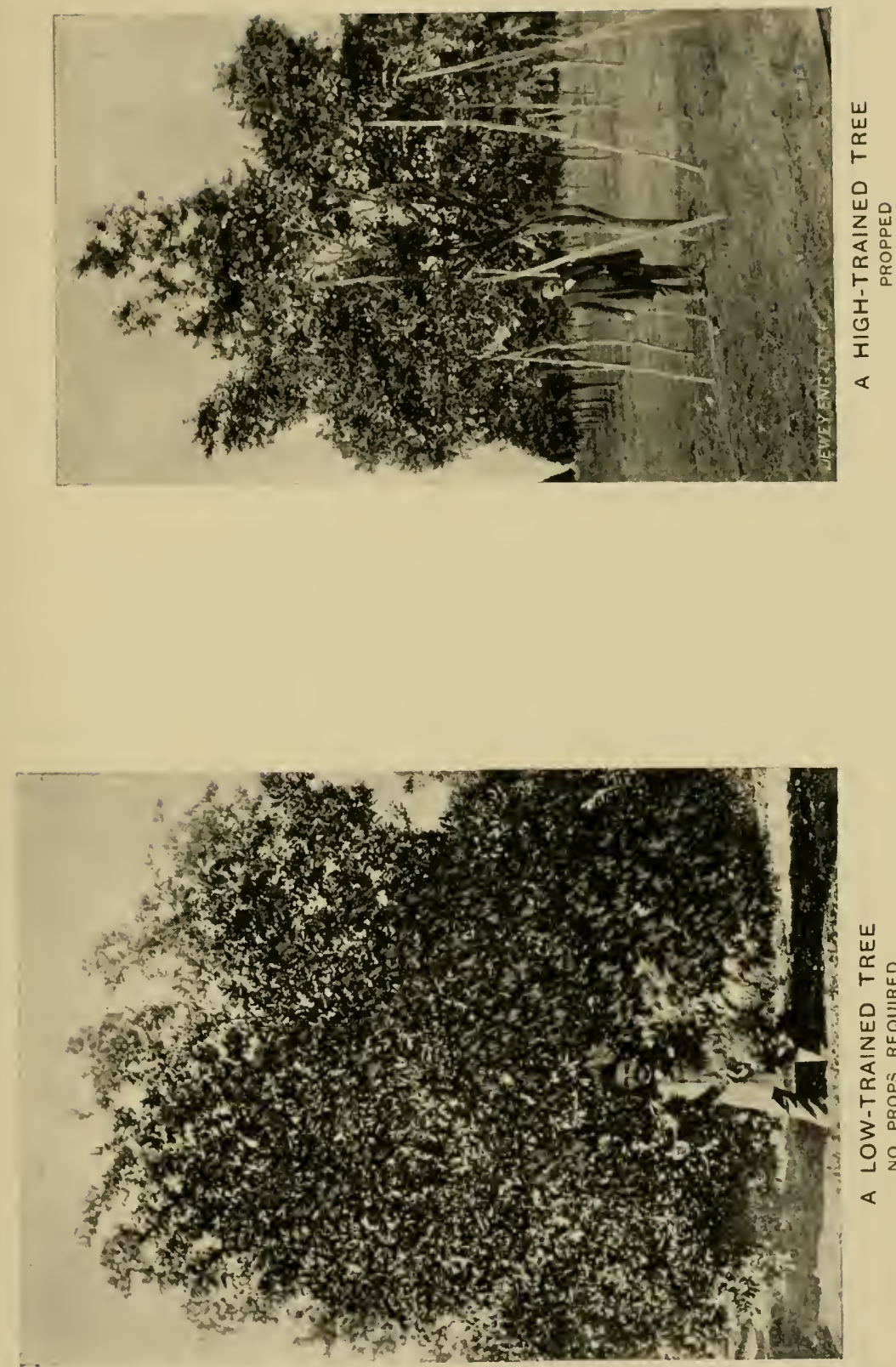

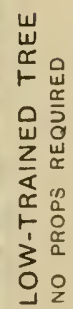






$\quad 00215313049$

1 9 